УДК 001.4

ББК 81.2-3

DOI: https://doi.org/10.17308/lic.2020.4/3075

\title{
СИСТЕМНЫЕ ОТНОШЕНИЯ В ТЕРМИНОЛОГИИ МИРОТВОРЧЕСКОЙ ДЕЯТЕЛЬНОСТИ ООН
}

\author{
Д. Л. Акимов \\ Филиал Военного учебно-научного центра военно-воздушных сил «Военно-воздушная академия \\ имени профессора Н. Е. Жуковского и Ю. А. Гагарина» в г. Сызрани
}

\section{SYSTEMIC RELATIONS IN THE TERMINOLOGY OF UN PEACEKEEPING ACTIVITIES}

\author{
D. L. Akimov \\ Branch of the Military Training and Scientific Center of the Air Forces «Air Academy \\ named after professor N. E. Zhukovsky and Yu. A. Gagarin" in Syzran
}

\begin{abstract}
Аннотация: в статье рассматриваются особенности формирования специальной лексики миротворческой деятельности ООН через призму отношений системы терминов миротворческой деятельности и терминологий других направлений деятельности (военной, дипломатической, юридической и др.). Рассмотрены различные подходы к понятию «термин», на основании которых предпринята попытка сформулировать определение, отражающее специфику конкретного вида профессиональной деятельности. Целью исследования является формирование представления о языке для специальных иелей миротворческой деятельности ООН. Предметом исследования является термин как основная лексическая единица языка для специальных иеелей миротворческой деятельности ООН. Предпринята попьтка классификации терминов миротворческой терминосистемы и сравнения их значений с терминами из других терминологий. В статье делается вывод о том, что термины, заимствованные из различных терминологий, включаются в тесные системные отношения внутри языка для специальных иелей миротворческой деятельности, при этом принимают значения, необходимые для функиионирования в данном виде профессиональной деятельности, тем самым формируют новый понятийный аппарат.

Ключевые слова: $О О Н$, миротворчество, язык для специальных иеелей миротворческой деятельности, термин, терминология, терминосистема.
\end{abstract}

\begin{abstract}
UN peacekeeping through the prism of relations between the system of terms of peacekeeping and terminologies of other areas of activity (military, diplomatic, legal, etc.). Various approaches to the concept of the term are examined, on the basis of which an attempt is made to formulate a definition that reflects the specifics of a particular type of professional activity. The aim of the study is to form a concept of language for special purposes of UN peacekeeping. The subject of the study is the term as the main lexical unit of the language for the special purposes of UN peacekeeping. An attempt was made to classify the terms of the peace term system and compare their meanings with terms from other terminologies. The article concludes that terms borrowed from various terminologies are included in close systemic relations within the language for special purposes of peacekeeping, while taking on the values necessary for functioning in this type of professional activity, thereby forming a new conceptual framework.

Key words: UN, peacekeeping, language for special purposes of peacekeeping, term, terminology, terminology system.
\end{abstract}

\section{Введение}

Российская Федерация как член ООН разделяет цели, определенные в ст. 1 ее Устава, и принимает активное участие в операциях по поддержанию мира под эгидой ООН. Кроме того, Россия также участвует и в других международных операциях, действуя

(C) Акимов Д. Л., 2020

Контент доступен под лицензией Creative Commons Attribution 4.0 License.

The content is available under Creative Commons Attribution 4.0 License. 
сугубо исходя из принципов, указанных в ст. 2 Устава [1].

Российские воинские контингенты и военные специалисты, направляемые для решения задач миссий ООН или примирения враждующих сторон на территории различных «горячих точек» планеты, проводят совместные действия с военнослужащими других государств, что требует от них профессионального общения. В качестве эффективного и апробированного средства коммуникации для решения задач международных военных операций в настоящей статье мы рассматриваем специальную лексику миротворческих миссий, проводимых под эгидой ООН.

Поддержание мира - одно из основных направлений работы ООН. Как любой вид деятельности миротворчество обладает специальной лексикой, которая служит для обеспечения профессиональной коммуникации между сотрудниками международных миссий по поддержанию мира. Ее развитие и усовершенствование при увеличении масштабов миротворческой деятельности под эгидой ООН является актуальной задачей.

С момента развертывания первой миссии ООН по поддержанию мира специальную лексику миротворческой деятельности составляют термины, преимущественно заимствованные из военной терминологии Вооруженных сил США и терминологии международных отношений, а языком, обслуживающим все без исключения миссии, является английский язык.

Международный характер миссий ООН по поддержанию мира оказывает особое влияние на лексику, так как не все военные наблюдатели являются носителями английского языка. Специалисты, направляемые в миссии, проходят обязательное обучение по стандартам ООН на территории своей страны в аккредитованных для этих целей учебных заведениях, где изучают историю ООН и миротворческих операций под эгидой ООН, страноведение, а также особенности работы в миссиях. Обучение проводится на английском языке.

Стоит отметить, что в процессе развития миротворческой деятельности ООН внутри сообщества военных наблюдателей неофициально сформировался так называемый «UN English» - язык, обслуживающий обыденную межличностную коммуникацию между сотрудниками миссии, основанный на классическом английском языке, но при этом учитывающий различный уровень знания языка международных специалистов.

Помимо межличностной коммуникации, сотрудники миссий ведут профессиональное общение, что повлияло на создание особого языка для специальных целей миротворческой деятельности.

Под языком для специальных целей миротворческой деятельности в данной работе следует понимать профессиональный язык, обслуживающий профессиональную коммуникацию международных специалистов и обеспечивающий одинаковое для всех понимание терминологии, применяемой в операциях ООН по поддержанию мира.

Специальная лексика операций по поддержанию мира в связи с особой спецификой, в отличие от других видов профессиональной лексики, практически лишена профессионализмов и преимущественно состоит из терминов, не допускающих двоякого понимания служебных аспектов деятельности.

\section{Понятие «термин» в словарях и в лингвистических исследованиях}

В контексте изучения языка для специальных целей миротворческой деятельности рассмотрим некоторые определения понятия «термин» в словарях и работах лингвистов.

Д. Н. Ушаков в своем «Толковом словаре современного русского языка» [2, с. 674] дает ряд определений слову «термин»:

1. В формальной логике - понятие, выраженное словом (филос.);

2. Слово, являющееся названием строго определенного понятия.

С. И. Ожегов [3, с. 795] рассматривает понятие «термин» как слово или словосочетание - название определенного понятия какой-нибудь специальной области науки, техники, искусства.

По определению А. А. Реформатского, «термины - это слова специальные, ограниченные своим особым назначением; слова, стремящиеся быть однозначными как точное выражение понятий и называние вещей» [4, с. 115].

Стандартизированное понятие слова «термин» дается в ГОСТ 7.0-99 «Информационно-библиографическая деятельность, библиография»: термин - слово или словосочетание, являющееся точным обозначением определенного понятия какой-либо области знания [5, с. 13].

В английском языке слово «термин» обозначается словом «term», в словаре Oxford Advanced Learner's Dictionary of Current English приводится следующее определение: term /noun - a word of phrase used as the name of sth., especially one connected with a particular type of language: technical/legal/scientific terms (термин/cyществительное - слово или фраза, используемая для названия чего-либо, особенно если оно связано с конкретным типом языка: технические/юридические/научные термины) [6, с. 1561].

А. В. Суперанская выделяет следующее определение слова «термин»: «Термин - это специальное слово (или словосочетание), принятое в про- 
фессиональной деятельности и употребляющееся в особых условиях. Термин - это словесное обозначение понятия, входящего в систему понятий определенной области профессиональных знаний. Термин - это основной понятийный элемент языка для специальных целей» [7, с. 14].

Определение «термина» с позиции терминоведения сформулировано В. М. Лейчиком следующим образом: «Термин - лексическая единица определенного языка для специальных целей, обозначающая общее - конкретное или абстрактное - понятие теории определенной специальной области знаний или деятельности» [8, с. 32].

В данных определениях отражены основные характеристики и назначение понятия «термин», но все определения рассматриваются в контексте общенаучной и профессиональной деятельности. Попытка дать более узкое определение понятия «термин» была предпринята с точки зрения терминоведения. Но и здесь это понятие рассматривается с точки зрения теории определенной деятельности, в то время как в контексте миротворческой деятельности термин необходимо рассматривать как с теоретической, так и с практической точки зрения.

Поэтому в рамках данной статьи на основании вышеуказанных определений постулируем следующее положение: термин - номинативная лексическая единица (слово или словосочетание) языка для специальных целей, служащая для точного называния понятий, в строго ограниченных рамках конкретной профессиональной коммуникации.

Как следует из данного определения, основным свойством термина является называние понятий. По мнению С. В. Гринева-Гриневича, «это свойство термина является наиболее важным, потому что оно обусловливает не только принадлежность термина к специальной области знания, но и все остальные его свойства» [9, с. 26].

Следующим свойством, вытекающим из данного положения, является ограниченность значения терминов строго заданным лексическим полем, так как один и тот же термин в разных областях деятельности может иметь отличные друг от друга значения.

Другим важным свойством термина, вытекающим из предыдущего положения, является наличие дефиниции, которая точно определяет значение термина. Наличие дефиниции гарантирует его однозначность и независимость от контекста. Также термин должен быть лишенным какой-либо экспрессии, т. е. быть стилистически нейтральным.

А. А. Реформатский утверждает следующее положение: «термины существуют не просто в языке, а в составе определенной терминологии» [4, с. 115]. А. А. Реформатский рассматривает терминологию как совокупность терминов данной деятельности, образующую особый сектор лексики, наиболее доступный сознательному регулированию и упорядочению. С. И. Ожегов определяет терминологию как совокупность, систему терминов [3, с. 795]. Определение терминологии синонимично определению терминосистемы, представленному в ГОСТ 7.0-99: терминосистема - организованная совокупность терминов в специальном языке определенной области знания [5, с. 13].

\section{Терминосистема миротворческой деятельности: основные термины}

Миротворчество, будучи составной частью военной деятельности, является в первую очередь политической операцией, нацеленной на достижение стабильности и поддержания мира между конфликтующими сторонами путем дипломатической деятельности военных специалистов и демонстрации присутствия международных военных контингентов. Эта особенность повлияла на формирование системы терминов этого вида деятельности.

Система терминов миротворческой деятельности сформировалась в процессе эволюции операций по поддержанию мира и обусловлена своей главной целью - обслуживание языка для специальных целей миротворческой деятельности. Эта система формировалась под влиянием военной терминологии при разрешении межгосударственных конфликтов на почве территориальных споров и дополнялась в результате увеличения количества случаев нарушения международного гуманитарного права и международных прав человека, гуманитарных кризисов и политической нестабильности в локальных конфликтах.

На различных этапах развития конфликта между странами или снятия напряжения между противоборствующими сторонами внутри государства, приводящего к нарушению Прав человека, а также Международного гуманитарного права, ООН прилагает максимальные усилия для деэскалации сложившейся кризисной ситуации путем проведения мероприятий, выраженных рядом терминов. Так, для предотвращения конфликта на ранних стадиях проводятся политические мероприятия и консультации в рамках Conflict prevention (предупреждения конфликта). Этот вид деятельности ООН заключается в раннем предупреждении, сборе информации и тщательном анализе факторов, приводящих к конфликту. В этот период может производиться превентивное развертывание сил ООН для обеспечения видимого присутствия.

Политические меры, предпринимаемые в период развития конфликта с целью «посадить враждующие стороны за стол переговоров», составляют так называемое peacemaking (миротворчество). В этот же 
период на основании резолюции Совета безопасности ООН в качестве принудительной меры возможно применение военной силы в рамках рeace enforcement (принуждения к миру).

Для оказания помощи в выполнении соглашений, достигнутых в ходе переговоров, а также сохранения и укрепления хрупкого мира применяется peacekeeping (поддержание мира).

В ходе развития операций по поддержанию мира с целью эффективного управления конфликтом и создания основы для устойчивого мира и развития производится ряд долгосрочных мер, входящих в состав peace-building (миростроительства).

Миротворческая терминосистема органически связана с военной терминологией на основании наличия военного компонента в составе миротворческих миссий ООН, который играет ключевую роль в выполнении мандата миссии. Мандат миссии - это законное основание для всех действий, которые предпринимаются в ходе миротворческой операции. Документ издается в резолюции Совета безопасности ООН и, по сути, ставит конкретные задачи компонентам (components of mission), входящим в состав миссии (военному, полицейскому, гражданскому компонентам), для достижения целей миссии. Также стоит особо отметить роль дипломатической терминологии в формировании системы терминов языка для специальных целей миротворческой деятельности, так как разработка и выполнение мандата миссии являются дипломатическими усилиями, в том числе и военных наблюдателей, для поддержания мира в кризисном регионе.

Анализ директивных документов ООН и методических пособий по подготовке военных наблюдателей выявил различия между толкованиями схожих терминов, предлагаемых для понимания непосредственно будущими военными наблюдателями, и терминами, представленными в тематических словарях. Лексические единицы, составляющие миротворческую терминосистему, условно можно разделить на подгруппы, называющие предметы этого вида деятельности. В данной статье делается попытка классифицировать термины, входящие в состав языка для специальных целей миротворческой деятельности, по функциональным группам с приведением репрезентативных примеров.

1. Термины, называющие различные группы людей.

United Nations Military Observers (UNMOs) are military officers assigned to serve with the United Nations on a loan basis by their Governments at the request of the Secretary-General to the United Nations. UNMOs are considered as "Experts on Missions for the United Nations" [10, p. 21]. (Военные наблюдатели ООН (ВНООН) - офицеры, назначенные на службу в ООН на основе передачи их правительством по запросу Генерального секретаря ООН. Военные наблюдатели считаются «Экспертами в миссиях ООН»). В свою очередь в англоязычном словаре дипломатических терминов “A Dictionary of Diplomacy” термин Military observer представлен как military observer an officer, usually from the army and of middling rank, seconded on an individual basis to serve with an observer group engaged on peacekeeping [11, p. 157] (Военный наблюдатель - офицер армии, обычно среднего звена, который в индивидуальном порядке откомандирован для работы в группе наблюдателей, занимающихся вопросами поддержания мира). Также данный термин синонимичен с общеупотребимым словом observer (наблюдатель). Одно из значений, приводимых для этого слова в словаре Oxford Advanced Learner's Dictionary of Current English, представлено следующим образом: observer - a person who watches and studies particular events, situations, etc. and is therefore considered to be an expert on them [6, p. 1017] (наблюдатель - лицо, которое наблюдает и изучает определенные события, ситуации и т. д. и поэтому считается экспертом по ним).

Spoilers are Individuals or groups that may profit from the spread or continuation of violence, or have an interest to disrupt a resolution of a conflict in a given setting [12, p. 46] (Спойлеры - это отдельные лица или группы, которые могут извлечь выгоду из распространения или продолжения насилия или заинтересованы в том, чтобы помешать разрешению конфликта в определенных условиях). Происхождение данного термина от общеупотребительного слова spoil verb 1 to change something good into something bad, unpleasant, useless, etc.; noun 2 the profits or advantages that somebody gets from being successful [6, p. 1453] (испортить глагол 1, превратить что-то хорошее в нечто плохое, неприятное, бесполезное и т. д.; существительное 2 прибыль или преимущества, которые кто-то получает от успеха).

Civilian is any person who is not or is no longer directly participating in hostilities or other acts of violence shall be considered a civilian, unless he or she is a member of armed forces or groups. In case of doubt whether a person is a civilian, that person shall be considered a civilian [13, p. 5] (Гражданское лицо - это любое лицо, которое не принимает или более не принимает непосредственного участия в военных действиях или других актах насилия, считается гражданским лицом, если только он или она не является членом вооруженных сил или группировок. В случае сомнений в том, является ли лицо гражданским лицом, это лицо считается гражданским лицом). Данный термин присутствует как в дипломатической, так и в военной терминологии. Dictionary of politics and government дает общее определение этого термина: civilian adjective 
referring to an ordinary citizen, who is not a member of the armed forces; noun an ordinary citizen who is not a member of the armed forces [14, p. 39] (Гражданский прилагательное, обращение к рядовому гражданскому лицу, не являющемуся членом вооруженных сил; существительное, рядовой гражданин, не являющийся членом вооруженных сил).

Refugees are persons who have fled their homes and have crossed an international border in that process as a result of armed conflict, persecution, systematic human rights violations, or natural disasters [15, p. 139] (Беженцы - это лица, которые покинули свои дома, в процессе чего пересекли международную границу в результате вооруженного конфликта, преследования, систематических нарушений прав человека или стихийных бедствий). Термин также используется в дипломатической и военной терминологии, при этом в военной терминологии этот термин определяется следующим образом: refugee - a person who, by reason of real or imagined danger, has left their home country or country of their nationality and is unwilling or unable to return [16, p. 446] (беженец - лицо, которое по причине реальной или воображаемой опасности покинуло свою родную страну или страну своего гражданства и не желает или не может вернуться), в то время как в дипломатической терминологии refugee определяется как a person who has left a country because of war or political or religious persecution [14, p. 207] (беженец - лицо, покинувшее страну из-за войны, политического или религиозного преследования). Как следует из представленных определений, для миротворческой терминосистемы ближе определение, данное дипломатической терминосистемой.

Internally displaced persons (IDPs) are persons who have fled their homes but stay within their country of residence and therefore remain within the jurisdiction of their home country [15, p. 139] (Внутренне перемещенные лица - это лица, покинувшие свои дома, но находящиеся в стране своего проживания и, следовательно, находящиеся под юрисдикцией своей страны). Термин широко распространен в военной сфере. Словарь вооруженных сил США дает следующее толкование данному термину: internally displaced person - any person who has left their residence by reason of real or imagined danger but has not left the territory of their own country [16, p. 267] (внутренне перемещенное лицо - любое лицо, которое покинуло свое место жительства по причине реальной или воображаемой опасности, но не покинуло территорию своей страны).

2. Термины, называющие основные виды деятельности миротворцев при проведении операций по поддержанию мира.

Observation (Observing) is the core function of a successful UNMO and requires the highest standards and competencies. The observer must be able to quickly locate, recognise and identify military and other related violations of established agreements between the parties $[17$, p. 28] (Наблюдение является основной функцией успешного ВНООН и требует самых высоких стандартов и компетенций. Наблюдатель должен быть способен быстро обнаруживать, распознавать и выявлять военные и другие связанные с ними нарушения установленных соглашений между сторонами). Данный термин произошел из общеупотребительного слова Observation - the act of watching sb/sth carefully for a period of time, especially to learn sth. [6, p. 1016] (Наблюдение - акт внимательного наблюдения за кем-то/чем-то в течение определенного периода времени, в особенности для изучения чего-либо). Общеупотребительный термин также передает особенности деятельности военных наблюдателей, хотя и не подразумевает их в своем определении.

Operational Patrol - A ground patrol consisting of a minimum three UNMOs and two patrol vehicles tasked to check local units or reconnoitre an area to ensure both parties are complying with the cease fire agreements. (Administrative Patrol purpose is to escort supply vehicles, transport personnel or equipment for maintenance or for any other administrative and logistical purpose) $[17$, p. 12] (Оперативное патрулирование - наземное патрулирование, состоящее как минимум из трех ВНООН и двух патрульных машин, которым поручено проверить местные подразделения или провести рекогносцировку района для обеспечения соблюдения обеими сторонами соглашений о прекращении огня. (Целью административного патрулирования является сопровождение транспортных средств снабжения, транспортного персонала или оборудования для технического обслуживания или для любых других административных и логистических целей.) Происхождение термина сугубо военное и произошло от термина patrol - a detachment of ground, sea, or air forces sent out for the purpose of gathering information or carrying out a destructive, harassing, mopping-up, or security mission [16, p. 401] (патруль - отряд сухопутных, морских или воздушных сил, направляемый с целью сбора информации или выполнения разрушительной, беспокоящей зачистки или миссии по обеспечению безопасности). Данный термин представлен с точки зрения сугубо военной направленности. Фактически патрули военных наблюдателей ООН занимаются сбором информации и своим присутствием и действиями призваны пресекать нарушение условий прекращения огня.

Good Offices is the authority and legitimacy afforded by one's moral stature or gained through one's position or function that allows one to perform beneficial acts for another. This authority and legitimacy allows individuals to act as third-party mediators in various types of disputes 
[12, p. 125] (Добрые услуги - это полномочия и законность, предоставляемые моральным статусом человека или приобретаемые благодаря его положению или функциям, которые позволяют ему совершать благотворные действия для другого. Эти полномочия и законность позволяют отдельным лицам выступать в качестве посредников в различных видах споров). Очень интересный и обширный дипломатический термин, получивший свое распространение благодаря деятельности ООН. В словаре дипломатических терминов дается более подробное определение этого термина: good offices: Diplomatic intervention by a "neutral" third party (or "facilitator") in an international or intrastate conflict which is usually limited to providing assistance in bringing the rival parties into direct negotiations but may extend to suggesting a "formula for a settlement". Good offices (bons offices) do not, however, extend to active participation in discussions once they are beyond the procedural stage; if this develops, as sometimes happens, the provision of good offices has changed into "mediation" [11, p. 102] (добрые услуги - дипломатическое вмешательство «нейтральной» третьей стороны (или «посредника») в международный или внутригосударственный конфликт, которое обычно ограничивается оказанием помощи в привлечении конкурирующих сторон к прямым переговорам, но может распространяться на предложение «формулы для урегулирования». Однако добрые услуги (полномочия) не распространяются на активное участие в дискуссиях, когда они выходят за рамки процедурной стадии; если это развивается, как это иногда случается, предоставление добрых услуг превращается в «посредничество»). Однако сам термин не имеет широкого распространения среди полевых сотрудников миссий ООН по поддержанию мира, но встречается в директивных документах и резолюциях Совета безопасности ООН.

3. Термины, называющие действия враждующих сторон.

Incident - those events or actions which pose a threat to human life, jeopardize good relations between the UN and the belligerent parties, or interfere with military observers exercising their official duties [17, p. 12] (Инцидент - те события или действия, которые представляют угрозу человеческой жизни, ставят под угрозу хорошие отношения между ООН и воюющими сторонами или мешают военным наблюдателям, выполняющим свои официальные обязанности). Данный термин миротворческой деятельности заимствован из военной терминологии: incidents - brief clashes or other military disturbances generally of a transitory nature and not involving protracted hostilities [16, p. 250] (инциденты - кратковременные столкновения или другие военные беспорядки, как правило, временного характера и не связанные с затяжными боевыми действиями).

Violation - the events or actions that constitute a clear and direct breach of the cease-fire agreement. (Type of violation: Alleged, Possible, Observed and Long Standing Violation/Lasting Confirmed Violation) [17, p. 13] (Нарушение - события или действия, которые представляют собой явное и прямое нарушение соглашения о прекращении огня. (Тип нарушения: предполагаемое, возможное, наблюдаемое и длительное нарушение/длительное подтвержденное нарушение.). Термин произошел от лаконичного дипломатического термина violation - the act of breaking a rule [14, p. 257] (нарушение - акт нарушения правил).

Allegations are accusations usually made by one belligerent against actions of the other which may or may not be against the cease-fire agreement. These allegations will have to be investigated by UNMOs [17, p. 11] (голословные заявления) - это обвинения, обычно выдвигаемые одним воюющим против действий другого, которые могут быть или не быть против соглашения о прекращении огня. Эти обвинения должны быть расследованы ВНООН). Данный термин произошел из юридической терминологии (наиболее часто встречается в Миссии Организации Объединенных Наций по проведению референдума в Западной Caxape): allegation - any statement of fact in a statement of case, affidavit, or indictment. In civil cases it is the duty of the party who makes an allegation to adduce evidence in support of it at trial, under the principle of «he who asserts must prove» [18, p. 23] (утверждение (голословное заявление) - любое изложение факта в изложении дела, аффидавите или обвинительном заключении. В гражданских делах сторона, выдвигающая обвинение, обязана представить доказательства в его поддержку на суде в соответствии с принципом «тот, кто утверждает, должен доказать»).

Cease-fire - a temporary stoppage of war, which may also be undertaken as part of a larger negotiated settlement. A cease-fire marking the permanent end of war is referred to as an armistice [12, p. 124] (Прекращение огня - это временное прекращение войны, которое также может быть предпринято в рамках более масштабного переговорного урегулирования. Прекращение огня, знаменующее окончательное окончание войны, называется перемирием). В контексте миротворческой деятельности термин происходит из дипломатической терминологии и трактуется следующим образом: ceasefire - an agreement to cease fighting, whether local or all along the armed front. There is usually an air of temporariness about such agreements, which is often borne out by events. Sometimes, with a view to supporting a ceasefire, a ceasefire line (CFL) is agreed; sometimes this is known 
as the "green line". A ceasefire may, perhaps via a truce, lead to an armistice [11, p. 30] (прекращение огня соглашение о прекращении боевых действий, будь то на местном уровне или по всему вооруженному фронту. Такие соглашения обычно носят временный характер, что часто подтверждается событиями. Иногда в целях поддержки прекращения огня согласовывается линия прекращения огня, иногда называемая «зеленой линией». Прекращение огня может через затишье привести к перемирию).

4. Термины, называющие оперативные документы, необходимые в работе миротворцев.

Peace Agreement is a formal treaty intended to end or significantly transform violent conflict [12, p. 126] (Мирное соглашение - это официальный договор, направленный на прекращение или существенное преобразование насильственного конфликта). Данный термин является синонимом дипломатического термина peace treaty - a treaty which brings a war to a conclusion [11, p. 182] (мирный договор - договор, который приводит к окончанию войны). Стоит отметить, что термин «мирный договор» относится к окончанию конфликтов между государствами, в то время как термин «мирное соглашение» рассматривается как на межгосударственном уровне, так и при разрешении локальных конфликтов.

Rules of Engagement / Directive on the Use of Force: Guiding documents, for the military and police components respectively, which define the degree of force that may be used and the manner in which it may be applied [13, p. 18] (Правила применения силы / Директива об использовании силы - это руководящие документы для военного и полицейского компонентов соответственно, которые определяют степень применения силы и способ ее применения). Термин относится к военной терминологии, в миротворческой деятельности он определяет действия личного состава контингентов ООН, так как военные наблюдатели не имеют оружия и не имеют права его применения. В словаре военных терминов трактуется как rules of engagement - directives issued by competent military authority that delineate the circumstances and limitations under which United States forces will initiate and/or continue combat engagement with other forces encountered. Also called ROE [16, p. 461] (Правила применения силы - директивы, изданные компетентными военными властями, которые определяют обстоятельства и ограничения, в соответствии с которыми силы Соединенных Штатов будут инициировать и/или продолжать боевое взаимодействие с другими встреченными силами. Также называется РОE).

Standing operating procedure is a set of instructions covering those features of operations which lend themselves to a definite or standardized procedure without loss of effectiveness. The procedure is applicable unless ordered otherwise. Also called SOP [16, p. 500] (Постоянная операционная процедура - набор инструкций, охватывающих те особенности операций, которые поддаются определенной или стандартизированной процедуре без потери эффективности. Процедура применима, если не указано иное. Также называется СОП). Данный термин часто употребляется в методических пособиях и руководящих документах по подготовке и проведению операций по поддержанию мира и относится к военной терминологии. В словаре военных терминов имеет такое же толкование, что и представленное в данной статье.

Представленная классификация является далеко не полной, но отражает всю сложность и многогранность языка для специальных целей миротворческой деятельности ООН.

\section{Заключение}

Таким образом, термины, заимствованные из других терминологий, а также из общеупотребительного языка, вошедшие в язык для специальных целей миротворческой деятельности, приобретают значения, необходимые для функционирования непосредственно в данном виде профессиональной деятельности и формируют новый понятийный аппарат. Именно поэтому при подготовке специалистов для миротворческих миссий ООН необходимо акцентировать внимание на понимании терминов именно в контексте данного вида деятельности.

Проведенный анализ показал важность формирования системных отношений в миротворческой терминологии и требует дальнейшего исследования, особенно в период активизации привлечения к миротворческой деятельности миссии ООН специалистов РФ.

\section{ЛИТЕРАТУРА}

1. Устав Организации Объединенных Наций и Статут Международного Суда. URL: https://www.un.org/ru/ charter-united-nations/

2. Толковый словарь современного русского языка / Д. Н. Ушаков. М. : Аделант, 2013. 800 с.

3. Толковый словарь русского языка / С. И. Ожегов, Н. Ю. Шведова. 4-е изд., доП. М. : А ТЕМП, 2006. 944 с.

4. Введение в языковедение : учебник для вузов / А. А. Реформаторский ; под ред. В. А. Виноградова. 5-е изд., испр. М. : Аспект Пресс, 2004. 536 с.

5. ГОСТ 7.0-99 Межгосударственный стандарт. Система стандартов по информации, библиотечному и издательскому делу. Информационно-библиотечная деятельность, библиография. Термины и определения (Дата введения 07.01.2000) // Стандарты по библиотечно-информационной деятельности / сост. Т. В. Захарчук, О. М. Зусьман. СПб., 2003. С. 11-38.

6. Hornby A. S. Oxford Advanced Learner's Dictionary of Current English / ed. by S. Wehmeier, phonetics editor 
M. Ashby. Sixth edition. Oxford University Press, 2000. $1791 \mathrm{p}$.

7. Суперанская А. В., Подольская Н. В., Васильева Н. В. Общая терминология : Вопросы теории / отв. ред. Т. Л. Канделаки. Изд. 6-е. М. : ЛИБРОКОМ, 2012. $248 \mathrm{c}$.

8. Лейчик В. М. Терминоведение : предмет, методы, структура. Изд. 3-е. М. : ЛКИ, 2007. 256 с.

9. Гринев-Гриневич С. В. Терминоведение : учеб. пособие для студ. высш. учеб. завед. М. : Академия, 2008. $304 \mathrm{c}$.

10. United Nations Military Observers Handbook / ed. by J. Breinstrup. United Nations, 2001. 125 p.

11. A Dictionary of Diplomacy / ed. by G. R. Berridge and A. James. Second edition. 2001. 270 p.

12. Principles and Guidelines for UN Peacekeeping Operations / ed. by Harvey J. Langholtz. Ph. D. Peace Operations Training Institute, 2010. 200 p.

13. DPKO/DFS Policy On The Protection Of Civilians In United Nations Peacekeeping. United Nations DPKO/ DFS, 2015.

14. Dictionary Of Politics And Government / ed. by P. H. Collin. Third edition. Bloomsbury Publishing Plc, 2004. 278 p.

15. Core Pre-Deployment Training Materials Operations / ed. by Harvey J. Langholtz. Ph. D. Peace Operations Training Institute, 2014. 346 p.

16. The Department of Defense Dictionary of Military and Associated Terms / ed. by Vice Admiral S. A. FRY. US Department of Defense. 2004.

17. MINURSO Handbook / ed. by Major General Muhammad Tayyab Azam. MINURSO HQ ; Laayuone, 2015. 137 p.

18. A Dictionary of Law / ed. by Elizabeth A. Martin. Fifth edition. Oxford University Press, 2001. 551 p.

\section{REFERENCES}

1. Charter of the United Nations and Statute of the International Court of Justice. Available at: https://www. un.org/ru/charter-united-nations/

2. Tolkovyj slovar' sovremennogo russkogo yazyka [Explanatory dictionary of the modern Russian language] / D. N. Ushakov. Mosow: Adelant, 2013. 800 p.

3. Tolkovyj slovar' russkogo yazyka [Explanatory dictionary of the Russian language] / S. I. Ozhegov, N. Y. Shvedova. 4th edition, supplemented. Moskow : A TEMP, 2006. 944 p.

4. Vvedenie v yazykovedenie : uchebnik dlya vuzov [Introduction to linguistics: a textbook for universities] /

Филиал Военного учебно-научного ичентра военно-воздушных сил «Военно-воздушная академия имени профессора Н. Е. Жуковского и Ю. А. Гагарина» в г. Сызрани

Акимов Д. Л., курсовой офичер-преподаватель специального факультета

E-mail: legat1987@mail.ru
A. A. Reformatorskij; edited by V. A. Vinogradova. 5th edition, revised. Moskow : Aspekt Press, 2004. 536 p.

5. GOST 7.0-99 Mezhgosudarstvennyj standart. Sistema standartov po informatsii, bibliotechnomu i izdatel'skomu delu. Informatsionno-bibliotechnaya deyatel'nost', bibliografiya. Terminy i opredeleniya [System of standards on information, librarianship and publishing. Information and librarian activity, bibliography. Terms and definitions] // Library Information Standards / compilers T. V. Zakharchuk, O. M. Zus'man. Sankt-Peterburg, 2003. Pp. 11-38.

6. Hornby A. S. Oxford Advanced Learner's Dictionary of Current English / edited by S. Wehmeier, phonetics editor M. Ashby. Sixth edition. Oxford University Press, 2000. $1791 \mathrm{p}$.

7. Superanskaya A. V. Obshhaya terminologiya : Voprosy teorii [General terminology: Questions of theory] / A. V. Superanskaya, N. V. Podol'skaya, N. V. Vasil'eva; executive editor T. L. Kandelaki. 6th edition. Moskow : LIBROKOM, 2012. 248 p.

8. Lejchik V. M. Terminovedenie : predmet, metody, struktura [Terminology: subject, methods, structure]. 3rd edition. Moskow : LKI, 2007. 256 p.

9. Grinev-Grinevich S. V. Terminovedenie : uchebnoe posobie dlya studentov vysshikh uchebnykh zavedenij [Terminology: a study guide for students of higher educational institutions]. Moskow : Academia, 2008. 304 p.

10. United Nations Military Observers Handbook / edited by Jorgen Breinstrup. United Nations, 2001. 125 p.

11. A Dictionary of Diplomacy / edited by G. R. Berridge and Alan James. Second edition. 2001. 270 p.

12. Principles and Guidelines for UN Peacekeeping Operations / edited by Harvey J. Langholtz. Ph. D. Peace Operations Training Institute, 2010. 200 p.

13. DPKO/DFS Policy On The Protection Of Civilians In United Nations Peacekeeping. United Nations DPKO/ DFS, 2015.

14. Dictionary Of Politics And Government / edited by P. H. Collin. Third edition. Bloomsbury Publishing Plc, 2004. 278 p.

15. Core Pre-Deployment Training Materials Operations / edited by Harvey J. Langholtz. Ph. D. Peace Operations Training Institute, 2014. 346 p.

16. The Department of Defense Dictionary of Military and Associated Terms / edited by Vice Admiral S. A. FRY. US Department of Defense. 2004.

17. MINURSO Handbook / edited by Major General Muhammad Tayyab Azam. MINURSO HQ ; Laayuone, 2015. 137 p.

18. A Dictionary of Law / edited by Elizabeth A. Martin. Fifth edition. Oxford University Press, 2001. 551 p.

Branch of the Military Training and Scientific Center of the Air Forces "Air Academy named after Professor N. E. Zhukovsky and Yu. A. Gagarin» in Syzran

Akimov D. L., Course Officer-teacher of the Special Faculty

E-mail:legat1987@mail.ru 
Поступила в редакиию 7 июля 2020 г.

Принята к публикаичи 25 сентября 2020 г.

\section{Для цитирования:}

Акимов Д. Л. Системные отношения в терминологии миротворческой деятельности ООН // Вестник Воронежского государственного университета. Серия: Лингвистика и межкультурная коммуникация. 2020. № 4. C. 19-27. DOI: https://doi.org/10.17308/lic.2020.4/3075
Received: 7 July 2020

Accepted: 25 September 2020

\section{For citation:}

Akimov D. L. Systemic relations in the terminology of UN peacekeeping activities. Proceedings of Voronezh State University. Series: Linguistics and Intercultural Communication. 2020. No. 4. Pp. 19-27. DOI: https://doi.org/10.17308/ lic. $2020.4 / 3075$ 